\title{
A Ortodontia na atuação odontogeriátrica
}

\author{
Karyna Martins do Valle-Corotti* ${ }^{*}$ Caio Vinícius Martins do Valle**, Leniana Santos Neves***, \\ José Fernando Castanha Henriques ${ }^{\star \star \star \star}$, Arnaldo Pinzan ${ }^{\star \star \star \star \star}$
}

\begin{abstract}
Resumo
Objetivo: este artigo tem como objetivo abordar as características do tratamento ortodôntico associado a uma atuação odontogeriátrica, pois devido a um aumento da expectativa de vida, um maior número de pacientes idosos tem procurado tratamento odontológico para uma reabilitação estética e/ou funcional. Metodologia: através de uma avaliação de dados presentes na literatura são abordados fatores como enfermidades sistêmicas, uso de medicamentos, condição da saúde bucal, quantidade de osso alveolar, motivação do paciente e estabilidade oclusal após a terapia ortodôntica. Para exemplificar o tratamento ortodôntico no paciente idoso são apresentados dois casos clínicos. Conclusões: o tratamento ortodôntico representa uma intervenção viável na atuação odontogeriátrica, desde que realizado com forças suaves, considerando as limitações de cada caso e respeitando as características inerentes a esta atuação.
\end{abstract}

Palavras-chave: Odontologia geriátrica. Ortodontia. Idoso. Saúde do idoso.

\section{INTRODUÇÃO}

Com os avanços da Medicina e da ciência, a expectativa de vida da população tem aumentado consideravelmente. De acordo com o IBGE, a expectativa de vida do brasileiro, que em 2004 era de 70,4 anos ao nascer, deve alcançar em 2050 o patamar de 81,3 anos, mesmo nível atual do Japão, primeiro país do mundo em esperança de vida. Como conseqüência, a cada dia um maior número de idosos, com 60 anos ou mais (OMS), se preocupa com os cuidados com a saúde e a estética. Neste aspecto está envolvida a classe odontológica que, aprimorando seus conhecimentos e desenvolvendo novos materiais, atende este público cada vez mais preocupado com a sua aparência e seu bem-estar.

A Odontogeriatria ou Odontologia Geriátrica consiste no ramo da Odontologia que enfatiza o cuidado bucal da população idosa, especificamente do atendimento preventivo e curativo de pacientes com doenças ou condições de caráter sistêmico e crônico, associadas a problemas fisiológicos, físicos ou psicológicos ${ }^{22}$. No Brasil, surgiu como uma nova especialidade em 2001, aprovada na II Assembléia Nacional das Especialidades Odontológicas (ANEO) ${ }^{7}$. Atualmente, as diversas especialidades odontológicas, em especial a Ortodontia, vêm se integrando com esta nova área odontológica, a Odontogeriatria, anteriormente restrita aos procedimentos de Periodontia e Prótese.

\footnotetext{
Mestre e Doutora em Ortodontia pela Faculdade de Odontologia de Bauru - USP. Professora Associada da Disciplina de Ortodontia da Universidade Cidade de São Paulo - UNICID.

** Mestre em Ortodontia pela Faculdade de Odontologia de Bauru - USP

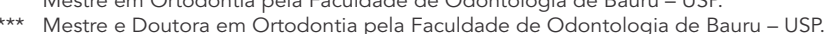

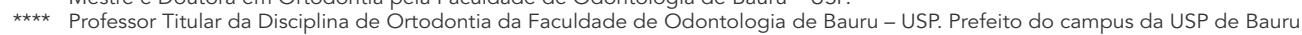

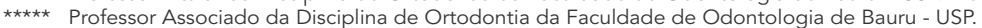


O paciente idoso apresenta, geralmente, perdas dentárias, próteses, restaurações extensas, alteração no tecido ósseo de suporte, sendo encaminhado ao ortodontista para um tratamento auxiliar a uma reabilitação bucal ou em casos de envolvimento estético, onde não estão indicados procedimentos restauradores $4,5,12,13,17$.

Neste caso torna-se primordial um planejamento multidisciplinar com bom relacionamento entre os profissionais envolvidos, observando as necessidades do paciente, as limitações do caso e os objetivos do tratamento, sempre considerando a motivação do paciente para este tratamento.

\section{PROPOSIÇÃO}

Este artigo apresenta como objetivo abordar as características do tratamento ortodôntico no paciente, apresentadas em diferentes trabalhos presentes na literatura. Este tipo de tratamento é também exemplificado pela descrição de dois casos clínicos.

\section{CARACTERÍSTICAS DO PACIENTE IDOSO Comportamentais}

Embora os aparelhos atuais sejam mais confortáveis e estéticos, existe ainda um preconceito por parte dos pacientes com mais idade em enfrentar a sociedade, realizando um tratamento comumente utilizado por indivíduos mais jovens. Entretanto é de comum acordo entre vários autores ${ }^{4,5,6,17}$ que estes pacientes são extremamente colaboradores com o tratamento, pontuais em suas consultas e responsáveis com a higiene bucal, quando bem orientados. A atenção do profissional dedicada ao paciente é de extrema importância, pois este aprecia um atendimento diferenciado, com informações detalhadas sobre cada fase do tratamento, colaborando para o seu sucesso ${ }^{4,5}$.

\section{Fisiológicas}

O envelhecimento individual é afetado em alto grau por fatores genéticos, dieta, condição social e ocorrência de doenças relacionadas com a idade, como a osteoporose e diabetes secundária. Ocorre uma diminuição do potencial de reparação de células como fibroblastos, osteoblastos e cementoblastos, importantes na movimentação dentária. Os osteoblastos de indivíduos idosos têm potenciais reprodutor e biossintético limitados, em comparação com os de indivíduos mais jovens, entretanto a atividade osteoclástica é a mesma em qualquer idade, o que diminui a capacidade regenerativa do periodonto ${ }^{4,23}$. Normalmente a densidade mineral e o metabolismo ósseo estão alterados e alguns autores ${ }^{15,16}$ consideram a possibilidade de uma movimentação mais rápida devido à menor resistência do osso, mas ainda não se sabe exatamente em quanto tempo o tratamento pode ser reduzido, principalmente porque as pesquisas são comumente realizadas em animais ${ }^{3}$.

\section{TRATAMENTO ORTODÔNTICO}

A movimentação ortodôntica no paciente com mais idade depende, principalmente, de um planejamento bem realizado, com objetivos precisos, a fim de realizar um tratamento ortodôntico simplificado, pois existe uma dificuldade deste paciente em tolerar o uso de aparelhos por períodos prolongados. No entanto, existem algumas limitações que devem ser consideradas durante o plano de tratamento.

\section{Limitações do tratamento}

Para o sucesso da movimentação ortodôntica faz-se necessário um exame clínico e radiográfico e uma anamnese bem realizados, que trarão informações importantes, colaborando na delimitação da atuação do profissional.

Fatores a serem observados:

1. Enfermidades sistêmicas avançadas.

2. Uso de medicamentos.

3. Má condição de saúde bucal.

4. Quantidade de osso alveolar.

5. Falta de motivação do paciente.

6. Impossibilidade de obtenção de estabilidade oclusal após a terapia ortodôntica. 
Entre as alterações sistêmicas, devemos considerar os envolvimentos hormonais como o hipoparatireoidismo (reabsorção óssea diminuída pela diminuição dos clastos), o hiperparatireoidismo (extrema atividade clástica que causa diminuição da densidade óssea) e a osteoporose. A osteoporose é um termo que denota aumento da porosidade do esqueleto resultante de uma redução da massa óssea por uma diminuição da matriz inorgânica deste tecido. Esta enfermidade ocorre, comumente, em mulheres, após a menopausa, pois nesta fase da vida o organismo enfrenta uma diminuição na secreção do estrógeno (hormônio secretado pelos ovários), que acelera o metabolismo ósseo com balanço negativo de cálcio ${ }^{9,16,25}$. Outra alteração sistêmica bastante comum é o diabetes, que provoca um distúrbio do funcionamento celular, diminuindo o seu metabolismo, com conseqüente diminuição da capacidade de reparação do tecidos ${ }^{9}$.

Portanto, deve-se ressaltar que, quando a saúde física geral do paciente está debilitada, deve-se reavaliar a necessidade do tratamento independentemente da idade. Entretanto, quando estas enfermidades estão controladas e o paciente está sob acompanhamento médico, não representam um obstáculo para a movimentação ortodôntica.

O paciente idoso comumente faz uso de algum medicamento para o controle de sua saúde. Um medicamento amplamente utilizado é o ácido acetilsalisílico, um anti-inflamatório conhecido como AAS; é um inibidor da síntese das prostaglandinas, as quais representam um dos mediadores da inflamação e colaboram para a atividade dos osteoclastos durante o movimento ortodôntico ${ }^{14,24}$. Muitas pesquisas têm sido realizadas com a intenção de esclarecer a influência de diferentes anti-inflamatórios na velocidade do movimento dentário, já que estes podem inibir a presença de osteoclastos, entretanto a velocidade do movimento dentário parece não diminuir significantemente ${ }^{24}$. Outro aspecto a ser considerado é o uso crônico de drogas corticosteróides que, quando administradas em doses supra-fisiológicas, induzem uma osteo- porose medicamentosa, o que pode causar uma movimentação ortodôntica mais rápida, mesmo com a aplicação de forças leves ${ }^{1}$. Embora se deva considerar a saúde do paciente e entender a importância em conhecer a atuação dos medicamentos utilizados por eles, a relação entre movimento ortodôntico e uso de medicamentos tem sido estudada em animais e a aplicação destes resultados em humanos deve ser cautelosa ${ }^{1,11}$. Contudo, a anamnese nestes pacientes precisa ser detalhada e bem interpretada.

A condição de saúde bucal é de extrema importância no tratamento ortodôntico. Tibério et al. ${ }^{21}$ observaram que aproximadamente $80 \%$ dos pacientes idosos necessitam de algum tipo de intervenção periodontal, como raspagens e intensificação dos cuidados de higiene; e aproximadamente $10 \%$ dos pacientes senis necessitam de tratamentos periodontais mais complexos. A movimentação ortodôntica deve ser realizada na ausência de doença periodontal ativa, caso contrário ocorre um agravamento da perda óssea já iniciada pela enfermidade periodonta ${ }^{10,16}$.

A quantidade de osso alveolar na região a ser movimentada ortodonticamente é um importante fator a ser observado, e determina o tipo de movimento a ser realizado ${ }^{8,18}$. Os pacientes idosos, em condições normais, apresentam uma diminuição das cristas ósseas característica do envelhecimento, que pode ser agravada pela presença de doenças periodontais ao longo da vida ${ }^{17,18}$. Os dentes com pouco suporte ósseo são passíveis de muita inclinação, pois o seu centro de resistência encontra-se deslocado para apical e para a sua movimentação são necessárias forças extremamente suaves. Conseqüentemente, os movimentos de corpo tornamse mais difíceis ${ }^{20}$. Segundo Harfin ${ }^{9}$, a quantidade de força que se utiliza tem relação direta com a quantidade de periodonto de inserção de cada dente.

A motivação do paciente representa não só um fator limitante, mas também determinante do tratamento, pois a má colaboração do paciente colo- 
ca em risco a estabilidade do mesmo ${ }^{2}$. Devido à idade avançada destes pacientes, muitos ainda recusam o tratamento ortodôntico e optam por tratamentos mais rápidos e menos dispendiosos, que levam a um maior número de extrações dentárias e à instalação de próteses mais extensas ${ }^{17}$.

\section{Objetivos do tratamento}

O tratamento ortodôntico no idoso geralmente limita-se à área do problema (tratamento parcial $)^{4,12,13}$ e apresenta objetivo estético e principalmente funcional, auxiliando na reabilitação de todo o sistema estomatognático. A distribuição equilibrada dos dentes representa um destes objetivos, tornando os espaços causados por ausências dentárias adequados para a colocação de implantes e próteses. As seis chaves de oclusão, almejadas para o paciente jovem, não são um objetivo deste tratamento, pois dificilmente serão alcançadas, dependendo das características oclusais de cada caso $^{16}$.

A maioria dos pacientes idosos apresenta alterações no periodonto de suporte e/ou proteção, sendo um importante objetivo do tratamento ortodôntico restabelecer a saúde periodontal a partir

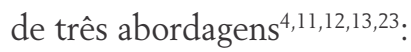

1. Corrigir defeitos ósseos verticais provocados por alteração na inclinação dentária ou por alterações radiculares como fraturas ou reabsorções externas que podem ser solucionadas com movimentos extrusivos.

2. Eliminar áreas retentivas à placa e que dificultam a higienização, geralmente provocadas por apinhamentos e giroversões.

3. Permitir a transmissão de forças oclusais no longo eixo do dente, eliminando os traumas oclusais.

\section{Contenção}

A contenção representa um dos pontos críticos do sucesso do tratamento no idoso. Nestes pacientes o processo osteoclástico ocorre de forma semelhante aos jovens, no entanto após a movi- mentação, quando o osso não está submetido a um estímulo, as respostas celulares são características da $3^{\mathrm{a}}$ idade, quando a neoformação óssea está diminuída. As doenças características da senescência também apresentam esta menor capacidade de neoformação. Isto indica que a estabilidade da movimentação estará comprometida, pois não haverá tempo suficiente para a formação de osso maduro, impedindo a recidiva. Neste caso tornase necessária uma contenção definitiva, com próteses fixas, resina associada a fios ortodônticos ou fibras de vidro, ou com outros materiais que unam e mantenham a posição de todos os dentes movimentados ${ }^{19}$.

Com base nestes princípios, serão demonstrados dois casos clínicos de pacientes idosos que optaram pelo tratamento ortodôntico para a resolução de problemas estéticos e funcionais.

\section{CASO CLÍNICO 1}

A paciente A. P. do gênero feminino, de 74 anos de idade, apresentava um diastema interincisivos no arco superior que estava progredindo, provavelmente devido à diminuição no periodonto de sustentação na região e trauma oclusal nos incisivos (Fig. 1, 2, 3). A possibilidade da realização de restaurações estéticas nos incisivos centrais para o fechamento do diastema foi descartada pela paciente, devido ao provável prejuízo da estética do sorriso, decorrente do tamanho exagerado destes dentes. Pelo mesmo motivo, o tratamento protético não foi considerado. Neste caso, a escolha da paciente foi o tratamento ortodôntico, por ser uma opção conservadora, que recuperaria a estética do seu sorriso sem alterar a forma do dentes.

A movimentação ortodôntica foi realizada com a colagem de braquetes da técnica Edgewise de primeiro pré-molar (dente 14) a canino (dente 23) do arco superior (Fig. 4, 5). Como a paciente não apresentava sobressaliência suficiente para a lingualização dos incisivos, que possibilitaria o fechamento do diastema, foi necessário aumentar a inclinação mesiodistal dos dentes para que os 


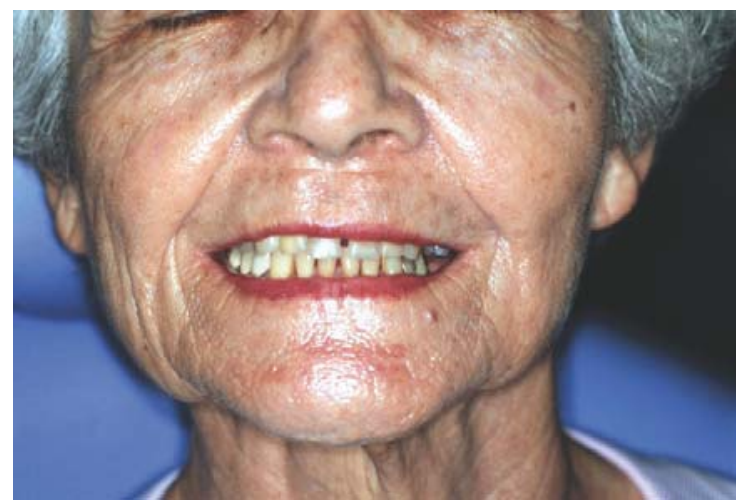

FIGURA 1 - Fotografia do sorriso da paciente antes do tratamento ortodôntico evidenciando o diastema interincisivos superiores, que constituía a sua queixa principal.

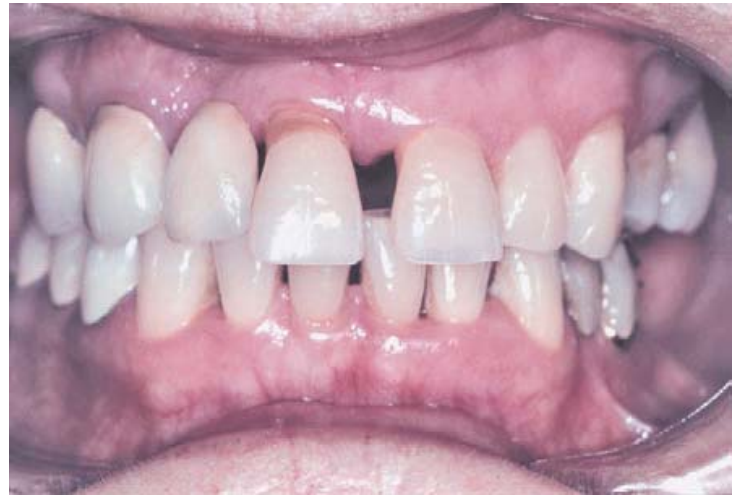

FIGURA 2 - Fotografia intrabucal inicial, em uma vista frontal.

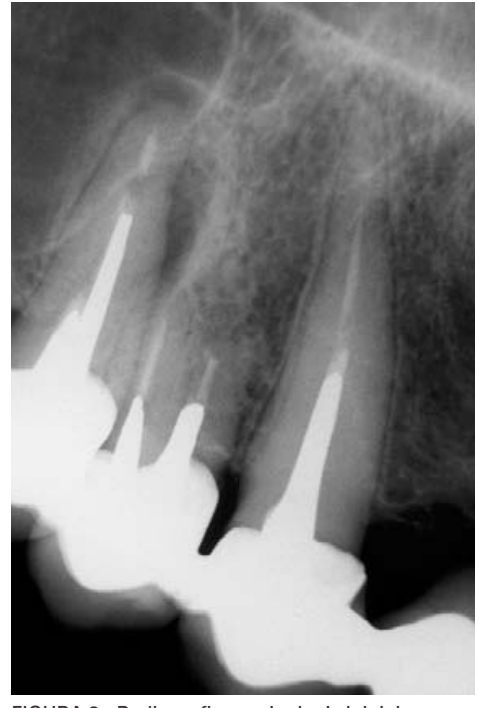

FIGURA 3 - Radiografias periapicais iniciais.
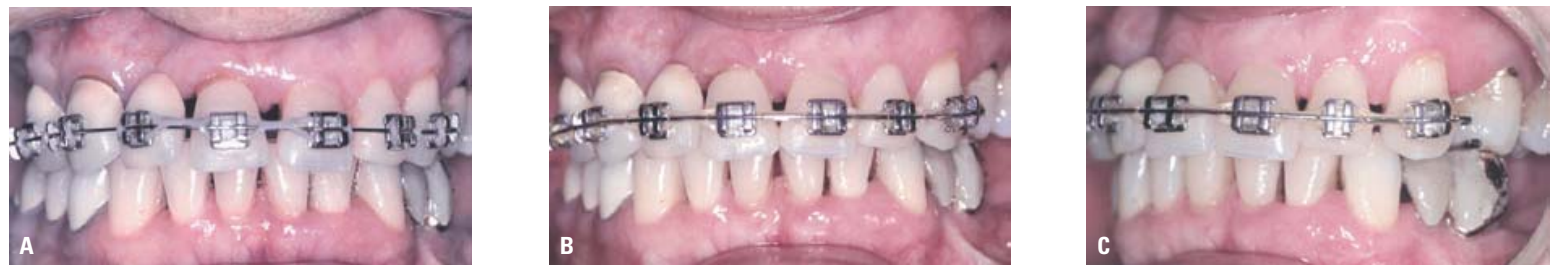

FIGURA 4 - Fotografias intrabucais intermediárias. A) Em uma fase mais precoce do tratamento, realizando o fechamento dos diastemas por meio de elástico corrente. B, C) Em uma fase mais avançada do tratamento, concluindo o fechamento dos espaços com elástico corrente.

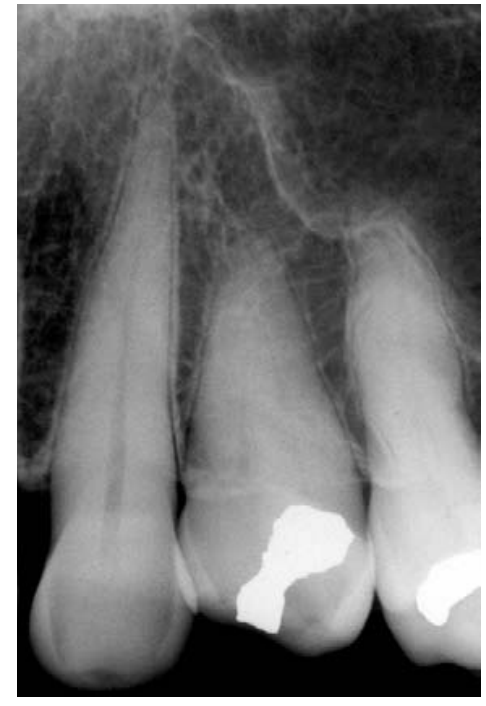

c. 

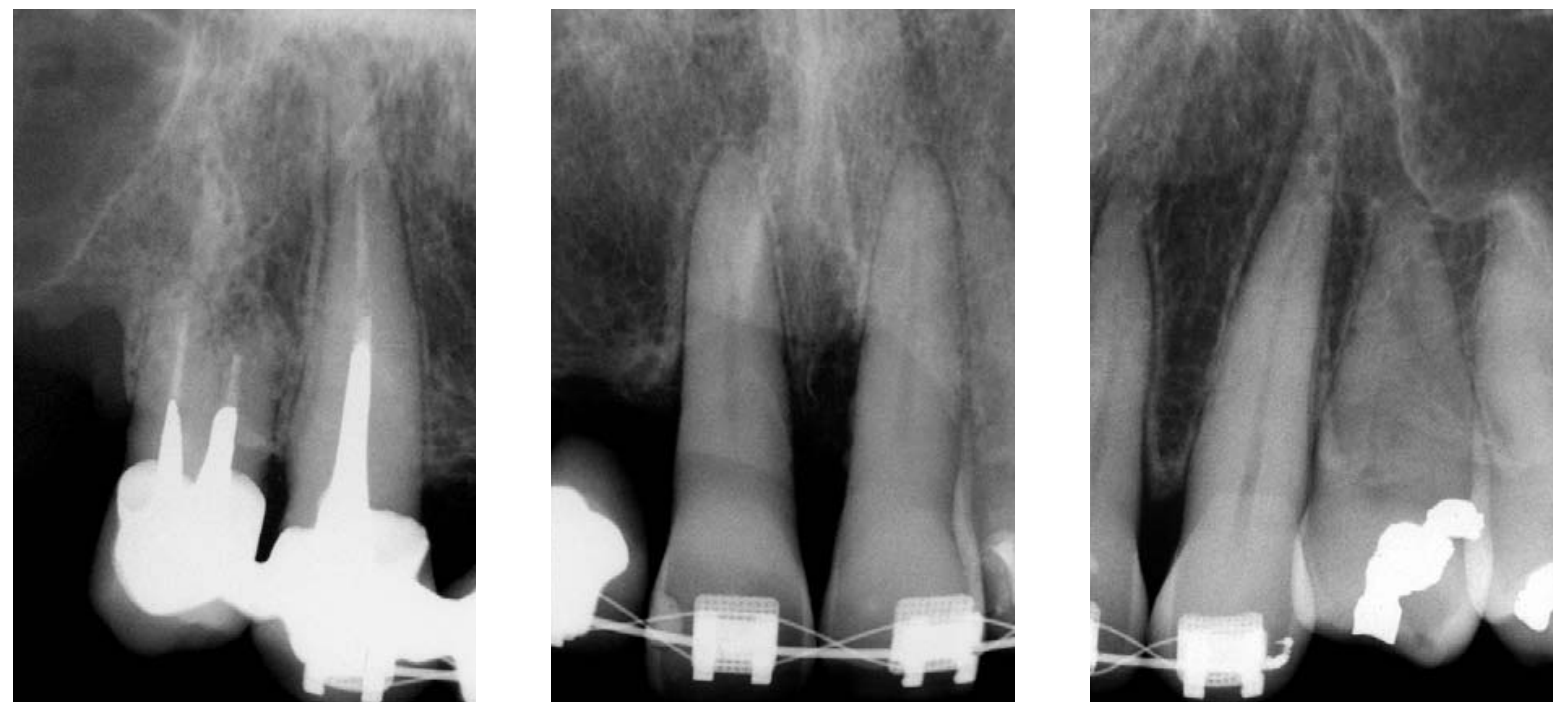

FIGURA 5 - Radiografias periapicais obtidas na fase final do tratamento ortodôntico.
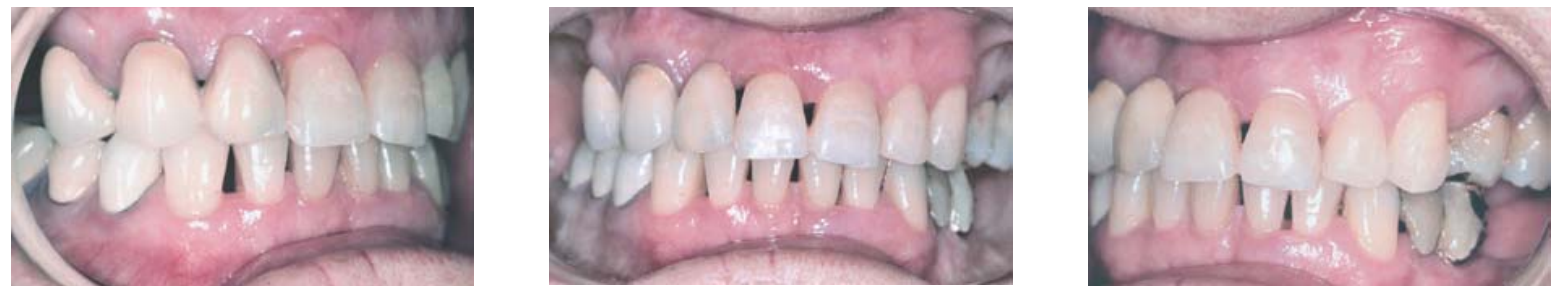

FIGURA 6 - Fotografias intrabucais finais.

mesmos ocupassem maior espaço no arco, colaborando para a redução do diastema. O trauma oclusal foi removido por meio de ajuste oclusal, com desgaste seletivo nos incisivos inferiores.

O diastema foi fechado com o uso de elástico corrente e fio de amarrilho 0,010 ". O tratamento durou 7 meses e as ativações foram realizadas a cada 40 dias. A contenção foi realizada com pequenas restaurações de resina composta, unindo os dentes pelos contatos interproximais (Fig. 6).

\section{CASO CLÍNICO 2}

Neste caso clínico observamos uma paciente do gênero feminino, com 62 anos de idade, que procurou a clínica integrada da Faculdade de Odontologia de Bauru para a realização de trata- mento protético e restaurador com a finalidade de recuperar a função mastigatória e a estética do seu sorriso (Fig. 7 - 10). A paciente optou pela realização do tratamento ortodôntico para o fechamento dos diastemas presentes em ambos os arcos, sendo esta sua principal queixa.

Foram utilizados braquetes da técnica Edgewise nos arcos superior e inferior até os pré-molares. O pré-molar superior direito não foi incluído na movimentação ortodôntica, devido à instalação de uma prótese fixa concomitante ao tratamento ortodôntico (Fig. 10). O fechamento dos diastemas foi realizado de maneira semelhante ao caso anterior, entretanto não foi necessário realizar ajuste oclusal, pois a redução do diastema no arco inferior e a inclinação para a lingual dos incisivos 

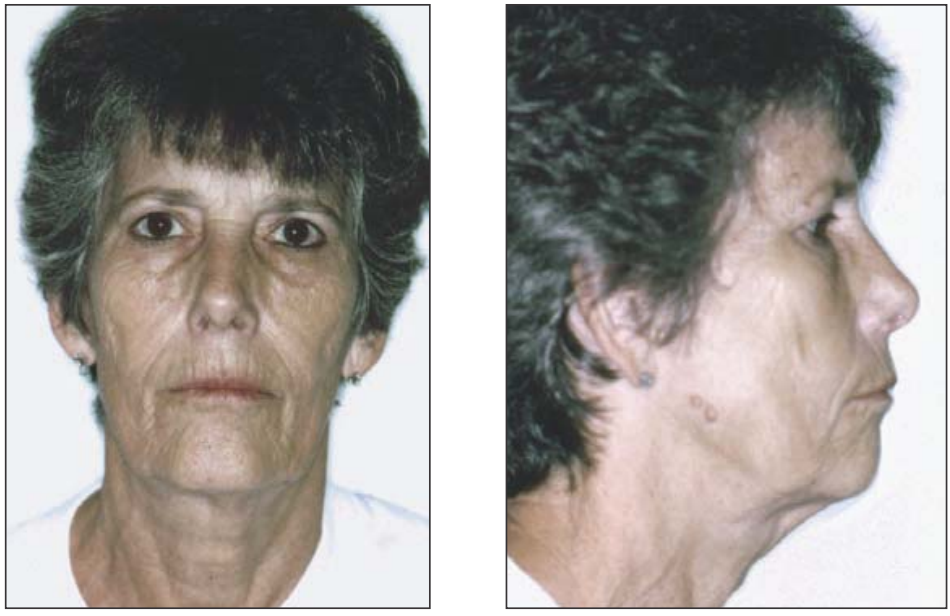

FIGURA 7 - Fotografias extrabucais iniciais.
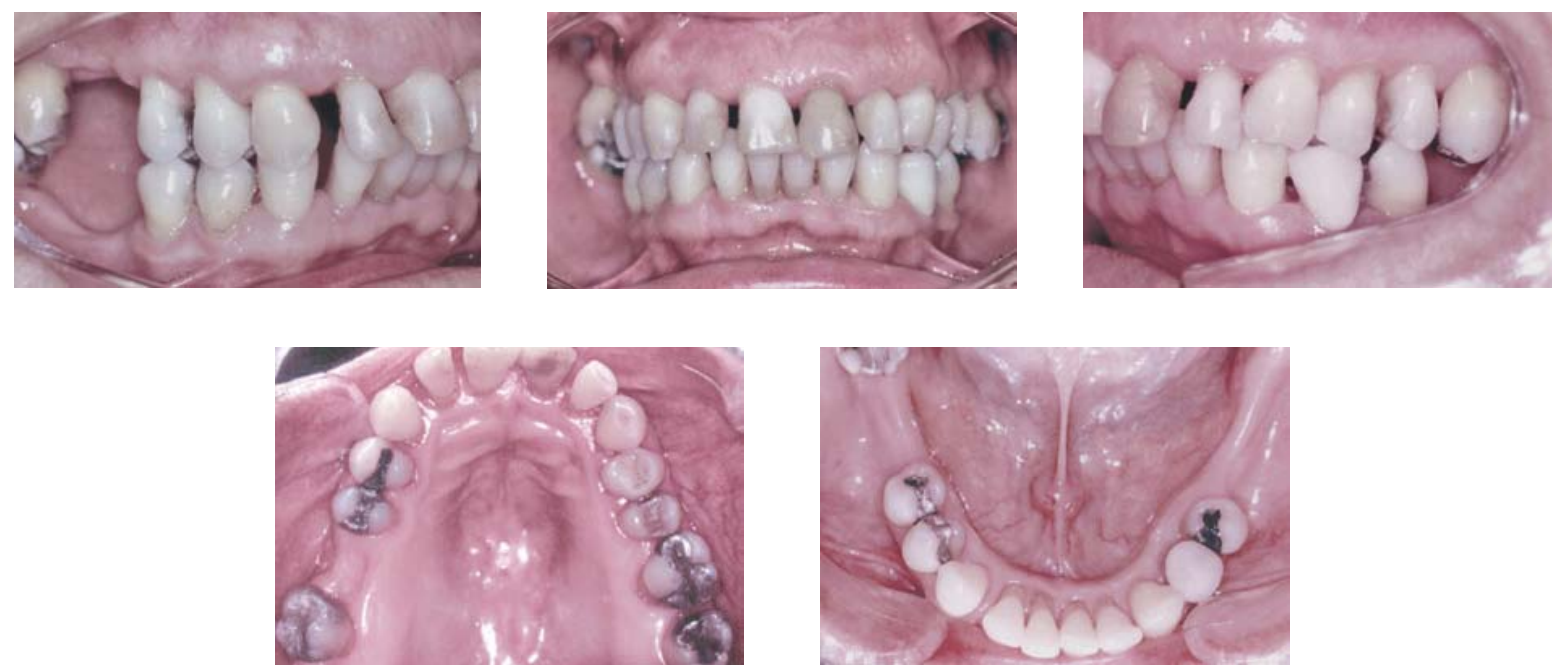

FIGURA 8 - Fotografias intrabucais iniciais.
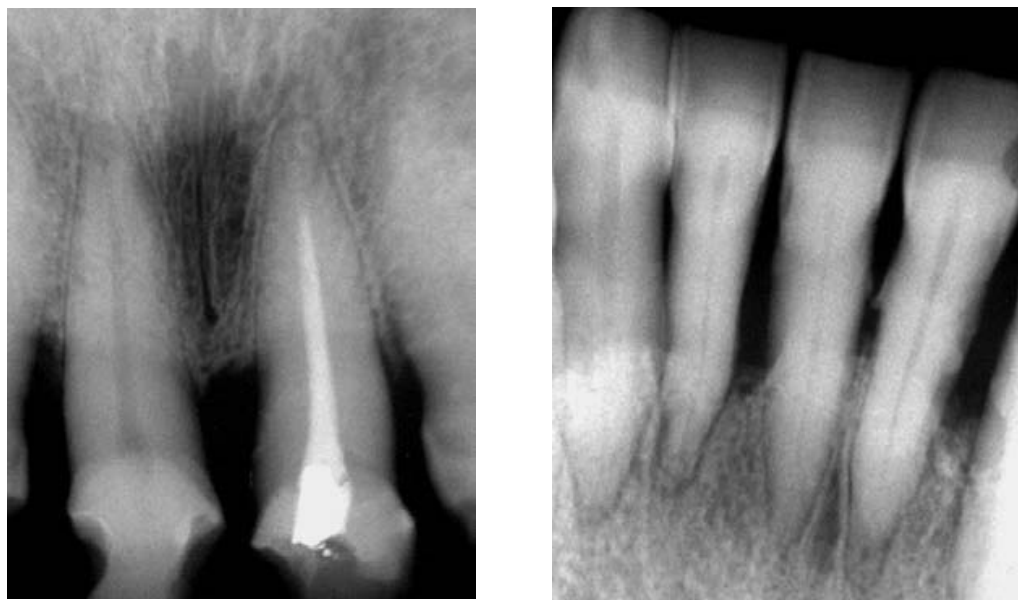

FIGURA 9 - Radiografias periapicais iniciais dos incisivos. 
inferiores corrigiram o contato excessivo na região anterior (Fig. 11, 12). O tratamento teve duração de nove meses e alcançou as expectativas da paciente, eliminando a realização de procedimentos invasivos. Após a finalização do tratamento ortodôntico, a paciente foi encaminhada para a colocação de uma prótese removível no arco inferior (Fig. 13, 14, 15).
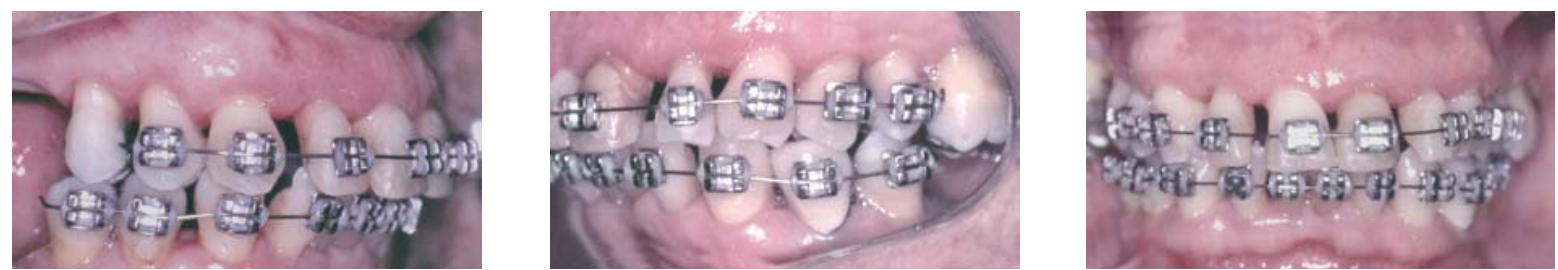

FIGURA 10 - Fotografias intrabucais intermediárias, em uma fase mais precoce do tratamento ortodôntico.

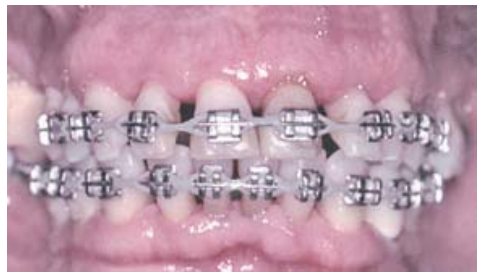

FIGURA 11 - Fotografia intrabucal intermediária, onde se observa o fechamento dos diastemas por meio de elástico corrente.
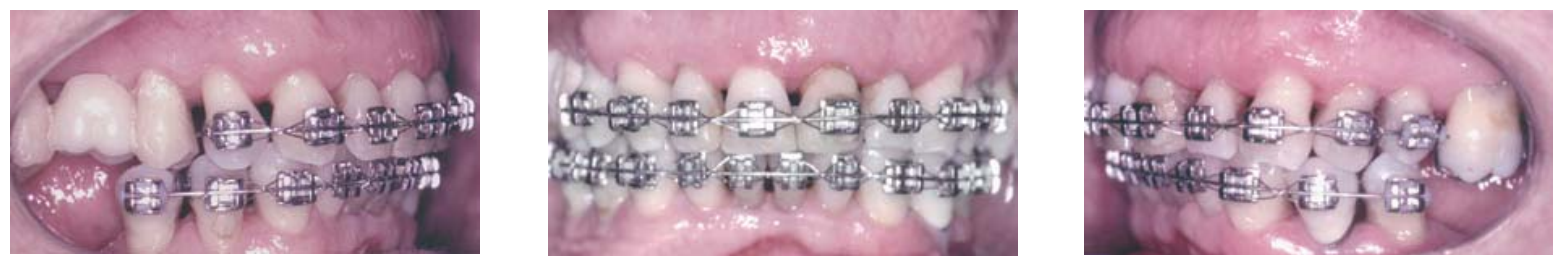

FIGURA 12 - Fotografias intrabucais intermediárias, na fase de finalização do tratamento ortodôntico.
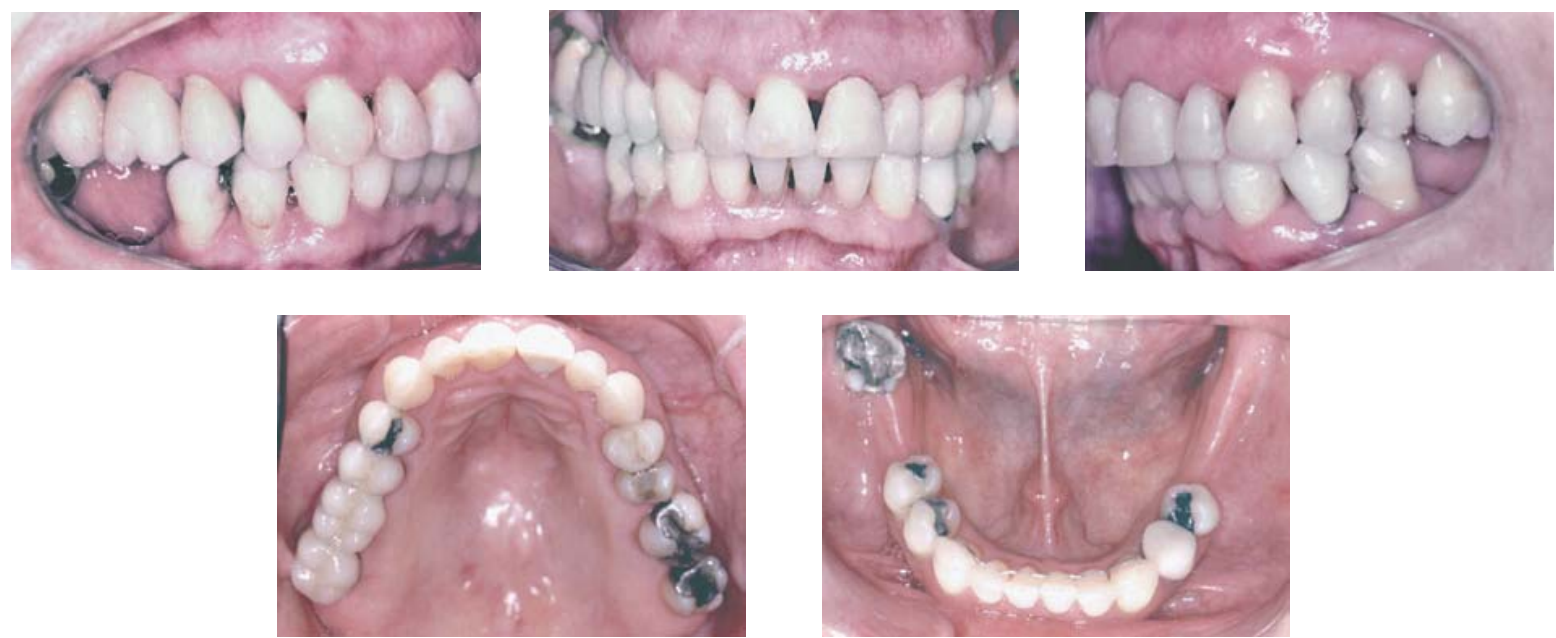

FIGURA 13 - Fotografias intrabucais finais. 


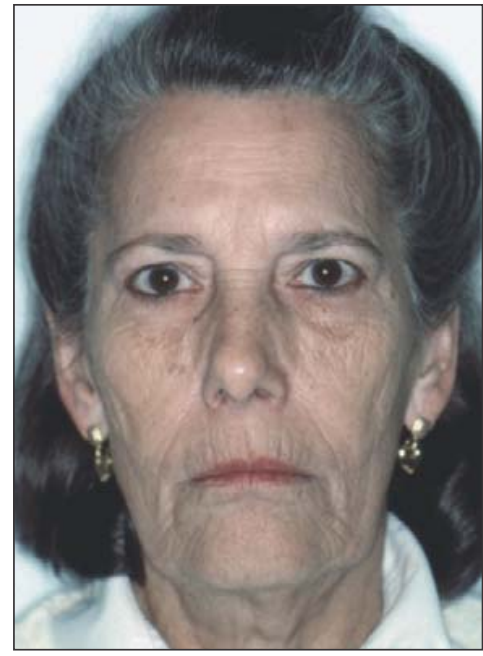

FIGURA 14 - Fotografias extrabucais finais.

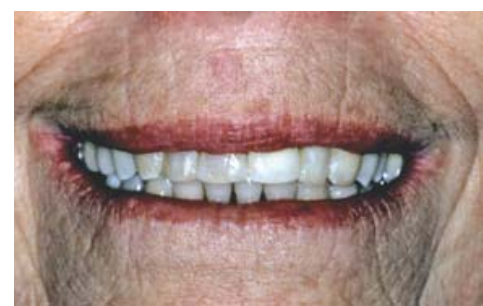

FIGURA 15 - Fotografias extrabucais do sorriso, evidenciando a estética obtida ao final do tratamento ortodôntico e reabilitador.
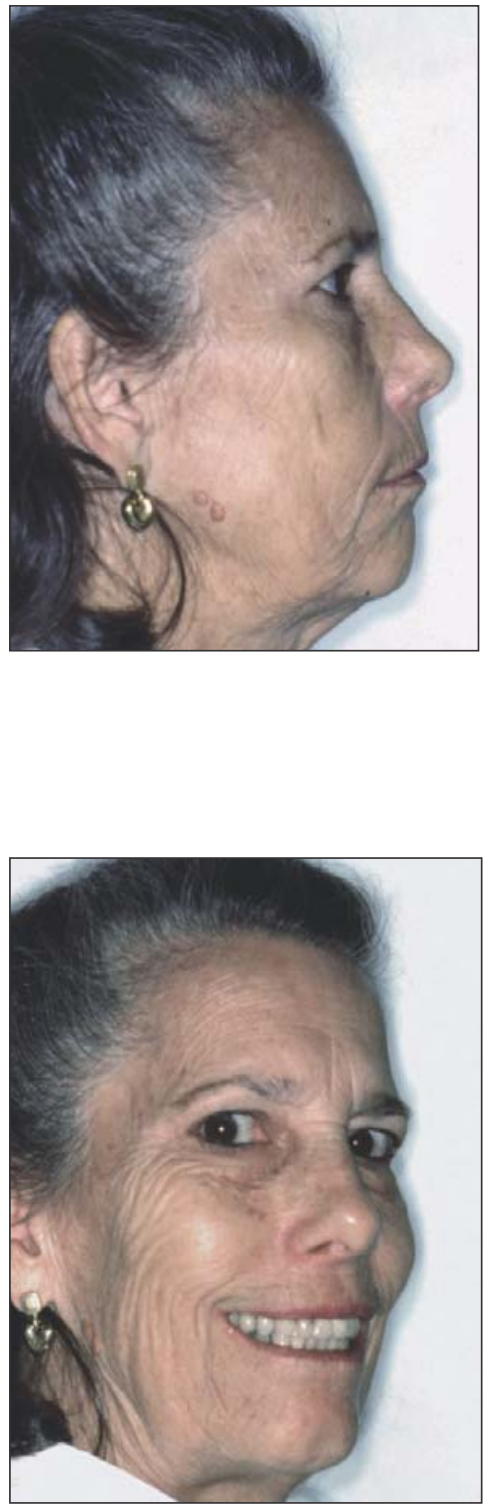

o tratamento estiver bem indicado e o paciente esclarecido e motivado, esse paciente se torna um ótimo colaborador e espera-se resultados bastante satisfatórios. 


\title{
The orthodontic treatment in older patients
}

\begin{abstract}
Objective: to approach the characteristics of the orthodontic treatment in aged patients, because the increase of life expectancy resulted in a bigger number of these kind of patients looking for orthodontic treatment. Methods: an evaluation of the literature show a series of factors as: systemic disease, medicine utilization, condition of the buccal health, amount of alveolar bone, patients' motivations and occlusal stability after the orthodontic therapy. To demonstrate the orthodontic treatment in the aged patient two clinical cases are presented. Conclusions: the orthodontic treatment represents a viable intervention in the aged patients, since that carried through with soft forces, considering the limitations of each case and respecting the inherent characteristics to these patients.
\end{abstract}

Key words: Geriatric dentistry. Orthodontics. Aged patient. Aging health.

\section{REFERÊNCIAS}

1. ASHCRAFT, M. B.; SOUTHARD, K. A.; TOLLEY, E. A. Effects of corticosteroids on tooth movement. Am. J. Orthod. Dentofacial Orthop., St. Louis, v. 102, no. 4, p. 310-319. 1992

2. BREECE, G. L.; NIEBERG, L. G. Motivations for adult orthodontic treatment. J. Clin. Orthod., Boulder, v. 20, no. 3,

p. 166-1671, Mar. 1986

3. BRIDGES, T.; KING, G.; MOHAMMED, A. Effect of age on tooth movement and mineral density in alveolar tissues of rat. Am. J. Orthod. Dentofacial Orthop., St. Louis, v. 93, no. 3, p. 245-250, Mar. 1988

4. CAPELOZZA FILHO, L.; BRAGA, S. A.; CAVASSAN, A. O.; OZAWA, T. O. Tratamento ortodôntico em adultos: uma abordagem direcionada. Rev. Dental Press Ortodon. Ortop. Facial, Maringá, v. 6, n. 5, p. 63-80, set./out. 2001.

5. FASTLICHT, J. Adult orthodontics. J. Clin. Orthod., Boulder, v. 16 , no. 9, p. 606-618, Sept. 1982

6. FRANKS, A. S. T.; HEDEGARD, B. Odontologia geriátrica. Rio de Janeiro: Labor do Brasil, 1977.

7. GARBIN, C. A. S.; MOIMAZ, S. A. S.; MACHADO, T. P. Odontologia geriátrica: hoje e sempre. Rev. Bras. Odontol., Rio de Janeiro, v. 60, n. 4, p. 281-284, jul./ago. 2003.

8. GERAMY, A. Alveolar bone resorption and the center of resistance modification: 3-D analysis by means of the finite element method. Am. J. Orthod. Dentofacial Orthop., St. Louis, v. 117, no. 4, p. 399-405, Apr. 2000.

9. GUYTON, A. C.; HALL, J. E. Tratado de fisiologia médica. 9. ed. Rio de Janeiro: Guanabara Koogan, 1997.

10. HARFIN, J. Entrevista. Rev. Dental Press Ortodon. Ortop. Facial, Maringá, v. 5, n. 5, p. 1-5, set/out. 2000.

11. HARFIN, J. Movimentos ortodônticos como complemento da terapêutica periodontal. In: INTERLANDI, S. Ortodontia: bases para iniciação. 4. ed. São Paulo: Artes Médicas, 1999. p. 73-95.

12. JANSON, M. R. P.; JANSON, R. R. P.; FERREIRA, P. M. Tratamento interdisciplinar I: considerações clínicas e biológicas na verticalização de molares. Rev. Dental Press Ortodon. Ortop. Facial, Maringá, v.6, n.3, p. 87-104, maio/jun. 2001.

13. JANSON, M. R. P. et al. Tratamento interdisciplinar II: estética e distância biológica: alternativas ortodônticas para remodelamento vertical do periodonto. Rev. Dental Press Ortodon. Ortop. Facial, Maringá, v. 7, n. 4, p. 85-105, jul./ago. 2002.

14. LEE, W. Effect of prostaglandins on tooth movement. Am. J. Orthod. Dentofacial Orthop., St. Louis, v. 98, no. 3, p. 231-241, Sept. 1990.
15. MIDGETT, R. J.; SHAYE, R.; FRUGE JR., J. F. The effect of altered bone metabolism on orthodontic tooth movement. Am. J. Orthod., St. Louis, v. 80, no. 3, p. 256-262, Sept. 1981

16. MIYAIJIMA, K.; NAGAHARA, K. Orthodontic treatment for a patient after menopause. Angle Orthod., Appleton, v. 66, no. 3, p.172-180, 1996.

17. NATTRASS, C.; SANDY, J. R. Ortodontia em adultos: uma revisão. Rev. Dental Press Ortodon. Ortop. Facial, Maringá, v. 4, n. 4, p. 71-77, jul/ago. 1999

18. NELSON, P. A.; ARTUN, J. Alveolar bone loss of maxillary anterior teeth in adult orthodontic patients. Am. J. Orthod. Dentofacial Orthop., St. Louis, v. 111, no. 3, p. 328-334, Mar 1997.

19. RADA, R. E. Mechanical stabilization in the mandibular anterior segment. Quintessence Int., Berlin, v. 30, no. 4, p. 243-248, Apr. 1999.

20. SMITH, R. J.; BURSTONE, C. J. Mecânica do movimento dentário. Ortodontia, São Paulo, v. 29, n. 2, p. 72-84, 1996.

21. TIBÉRIO, D.; SANTOS, M. T. B. R.; RAMOS, L. R. Estado periodontal e necessidade de tratamento em idosos. Rev. Assoc. Paul. Cir. Dent., São Paulo, v. 59, n. 1, p. 69-72, jan./fev. 2005.

22. WERNER, C. et al. Odontologia geriátrica. Um diagnóstico epidemiológico. Rev. Fac. Odontol. Lins, Lins, v. 11, n. 1, p. 62-70, jan./jun. 1998.

23. WILLIAMS, S. et al. The orthodontic treatment of malocclusion in patients with previous periodontal disease. Br. J. Orthod. Oxford, v. 9, no. 4, p. 178-184, Oct. 1982.

24. WONG, A.; ERIC, C.; REYNOLDS, E. C.; WEST, V. C. The effect of acetylsalicylic acid on orthodontic tooth movement in the guinea pig. Am. J. Orthod. Dentofacial Orthop., St. Louis, v. 102 , no. 4 , p. $360-3655,1992$.

25. YAMASHIRO, T.; TAKANO-YAMAMOTO, T. Influences of ovariectomy on experimental tooth movement in the rat. J. Dent. Res., Alexandria, v. 80, no. 9, p.1858-1861, Sept. 2001.

\section{Endereço para correspondência}

Karyna Martins do Valle-Corotti

Rua José Ferreira Marques $n^{\circ} 10-10$, apto 64

CEP: 17.012-200 - Vila Universitária - Bauru/SP

E-mail:vallek@uol.com.br 